\title{
Esophagobronchial fistula after sleeve gastrectomy successfully treated by endoscopic submucosal dissection and over-the-scope clip
}

Sleeve gastrectomy is a simple bariatric procedure that can sometimes be associated with serious complications. Among these, gastrobronchial or esophagobronchial fistula is rare (its incidence is $0.2 \%$ ) but is challenging to treat, frequently leading to left lower lobectomy [1]. To the best of our knowledge, successful endoscopic management of such a fistula following bariatric surgery has never been reported.

We present the case of a 28 -year-old patient who underwent a sleeve gastrectomy complicated 2 days later by a gastrobronchial fistula with subphrenic and pulmonary abscess ( $\mathbf{F i g . 1}$ ). Drainage by pigtail drain and closure with an endoscopic over-the-scope clip (OTSC) failed and an esophagojejunal Roux-en-Y anastomosis was performed. One month later, CT scan showed reopening of the fistula between the esophagojejunal anastomosis and the pulmonary abscess ( Fig.2). After 3 months of drainage by pigtail catheter, with persistent fistula ( $\triangleright$ Fig.3) and cough, the patient was referred to our unit for endoscopic treatment. We attempted endoscopic submucosal dissection (ESD) around and into the fistula tract followed by closure with an OTSC [2,3] ( V Video 1). Removal of the mucosal scar tissue by ESD favored new healing of the fistula orifice and the OTSC system allowed the edges to be closed. Oral intake was allowed on day 1. At 3 months later the patient was still asymptomatic, with complete resolution of the fistula and spontaneous migration of the OTSC shown on CT scan ( $>$ Fig.4). Endoscopic procedures are a popular choice in the management of sleeve gastrectomy complications because they are minimally invasive and have a good success rate (between $50 \%$ and $83 \%$ [4]). However, esophagobronchial or gastrobronchial fistulas can be challenging to treat. ESD followed by OTSC could be an option to obtain clinical resolution of

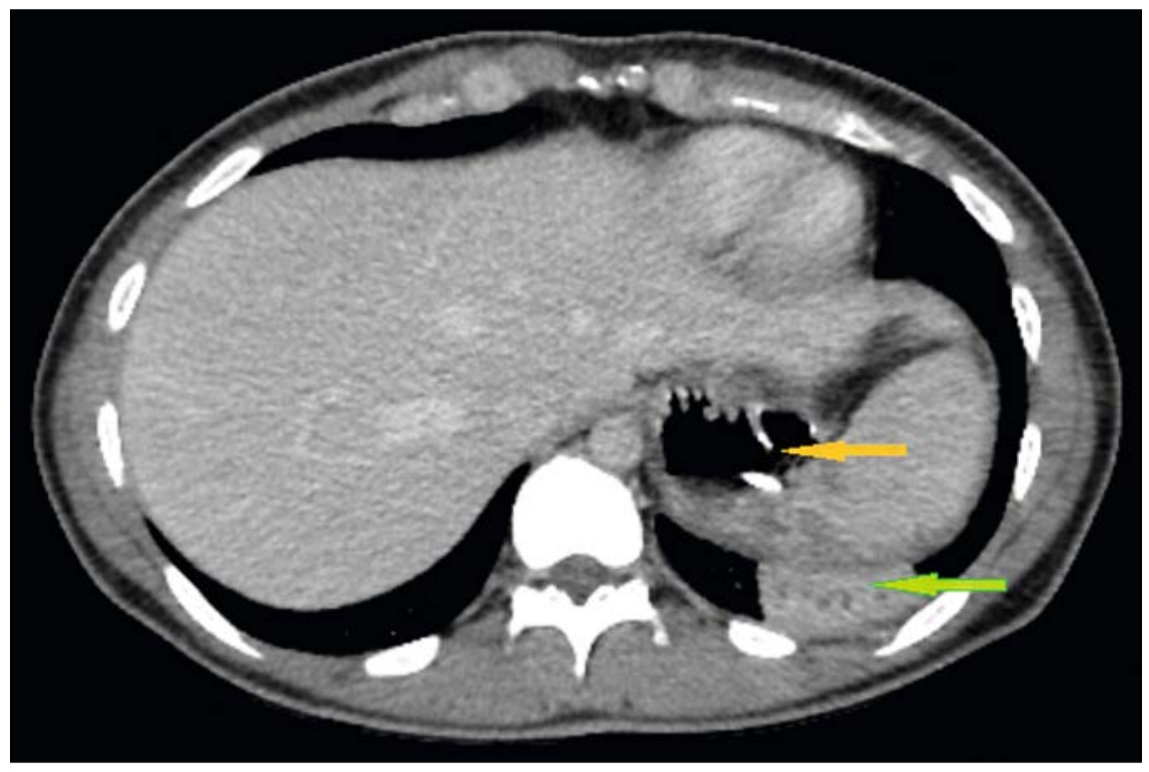

- Fig. 1 Gastrobronchial fistula with subphrenic abscess (yellow arrow) and left inferior pulmonary abscess (green arrow).

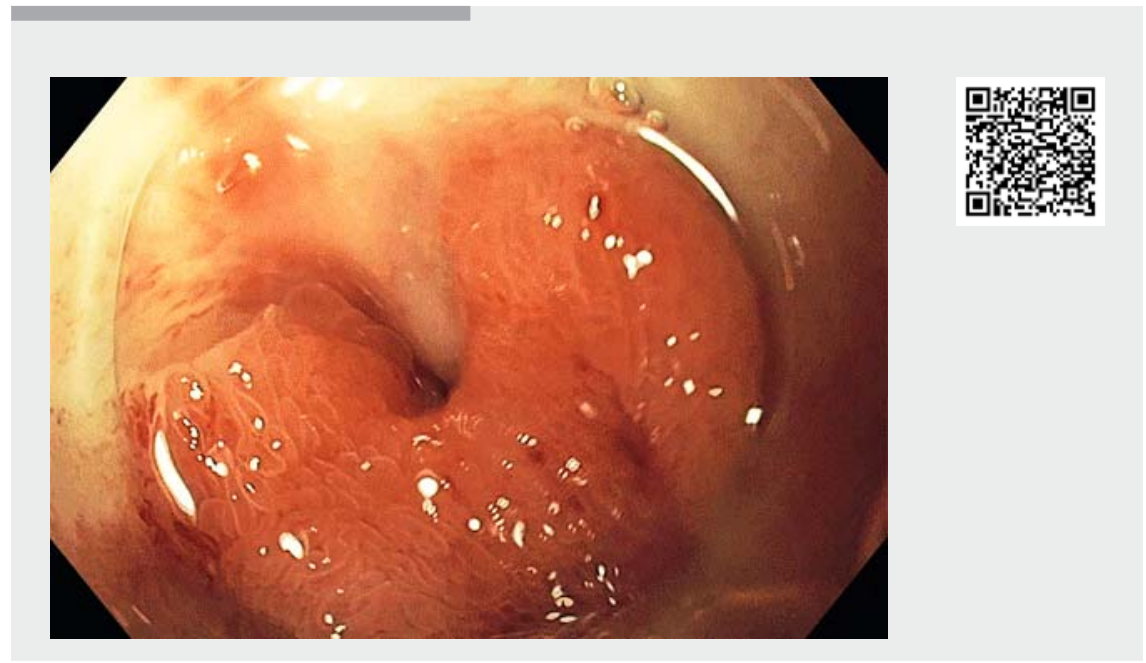

$\nabla$ Video 1 Endoscopic treatment of chronic fistula after sleeve gastrectomy by means of endoscopic submucosal dissection and an over-the-scope clip system.

these rare but severe fistulas following bariatric surgery.

Endoscopy_UCTN_Code_TTT_1AO_2AI

\section{Competing interests}

None 


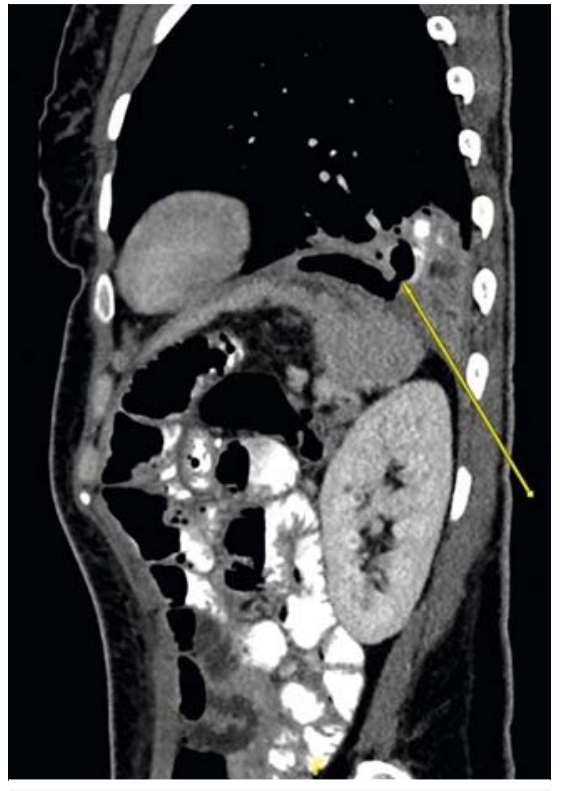

- Fig. 2 The fistula has reopened between the posterior part of the esophagojejunal anastomosis and the pulmonary abscess (yellow arrow).

The authors

Marina Ciochina ${ }^{1}$, Miruna Cruceru' ${ }^{1}$, Jérôme Rivory ${ }^{1}$, Maud Robert ${ }^{2}$, Nada Nargues ${ }^{3}$, Arnaud Pasquer ${ }^{2}$, Mathieu Pioche ${ }^{1}$

1 Department of Endoscopy and Gastroenterology, Pavillon L, Edouard Herriot Hospital, Lyon, France

2 Department of General Surgery, Edouard Herriot Hospital, Lyon, France

3 Department of Anesthesiology, Edouard Herriot Hospital, Lyon, France

\section{Corresponding author}

\section{Mathieu Pioche, MD, PhD}

Endoscopy Unit, Digestive Disease Department, Pavillon L, Edouard Herriot Hospital, 69437 Lyon Cédex, France mathieu.pioche@chu-lyon.fr

\section{References}

[1] Sakran N, Assalia A, Keidar A et al. Gastrobronchial fistula as a complication of bariatric surgery: a series of 6 cases. Obes Facts 2012; 5: $538-545$

[2] Wallenhorst T, Jacques J, Bouguen G et al. Successful closure of a rectal fistula of Crohn's disease using endoscopic submucosal dissection combined with an over-thescope clip. Am J Gastroenterol 2019. doi:10.14309/ajg.0000000000000366

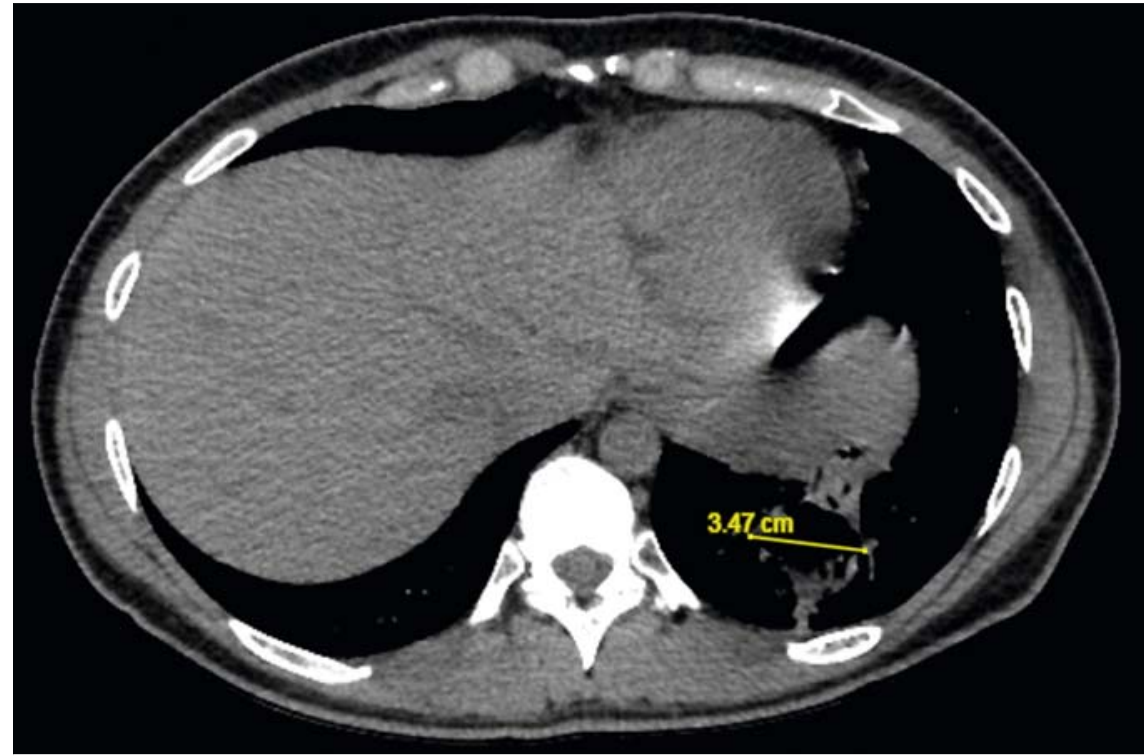

Fig. 3 Left esophagobronchial fistula persists with a left inferior pulmonary collection after 3 months of drainage by pigtail catheter.

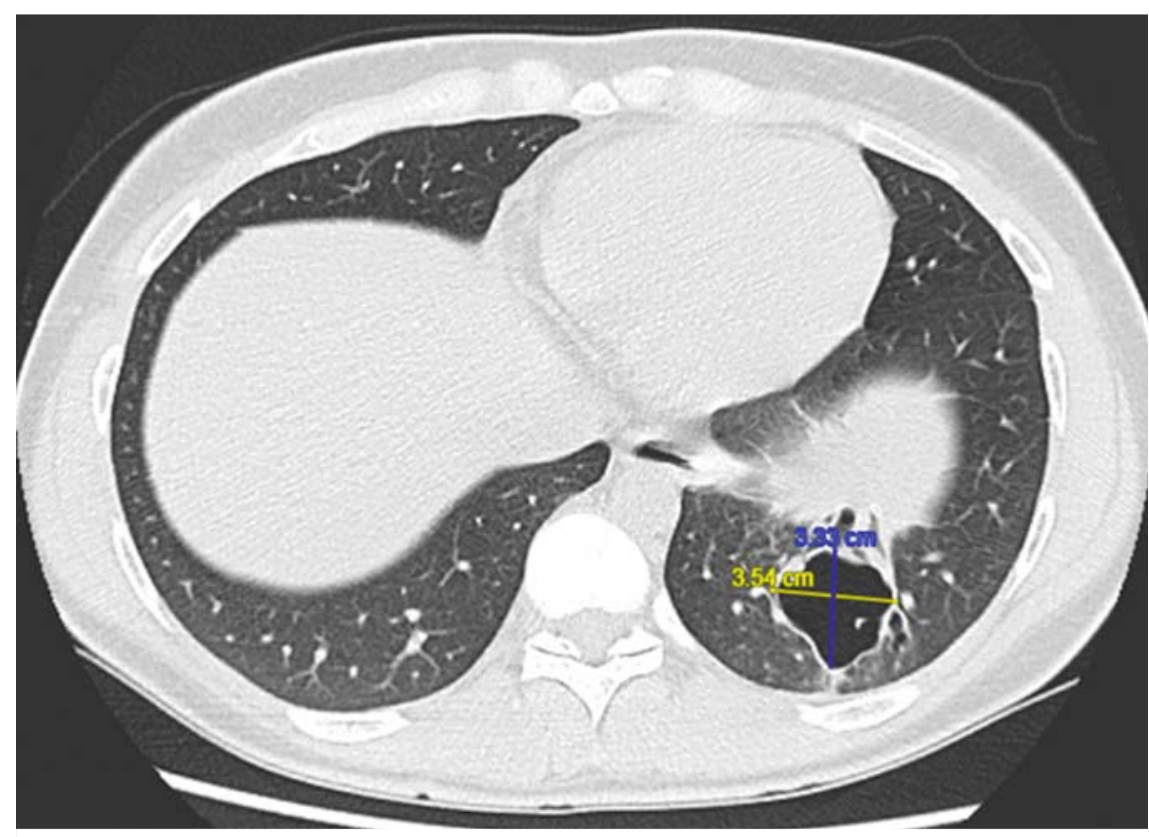

- Fig.4 Pulmonary excavation is stable with no visible esophagobronchial fistula.

[3] Gay-Chevallier S, Lupu A, Rivory ] et al. Closure of non-healing gastrocutaneous fistula after percutaneous endoscopic gastrostomy by endoscopic submucosal dissection and over-the-scope clip. Endoscopy 2019; 51: E125-E126

[4] Anastasiou J, Hussameddin A, Al Quorain A. Mind the gap: successful endoscopic closure of a large gastric sleeve leak using an endoscopic stent and over-the-scope clips. Case Rep Gastroenterol 2017; 11: 763 - 768

\section{Bibliography}

DOI https://doi.org/10.1055/a-1011-4092

Published online: 27.9.2019

Endoscopy 2020; 52: E100-E101

(c) Georg Thieme Verlag KG

Stuttgart · New York

ISSN 0013-726X 